\title{
Evaluation of cellulose degrading efficiency of some fungi and bacteria and their biofilms
}

\author{
K.M.D. Gunathilake ${ }^{1}$, R.R. Ratnayake ${ }^{1 *}$, S.A. Kulasooriya ${ }^{1}$ and D.N. Karunaratne ${ }^{2}$ \\ ${ }^{I}$ Institute of Fundamental Studies, Hantana Road, Kandy. \\ ${ }^{2}$ Department of Chemistry, Faculty of Science, University of Peradeniya, Peradeniya.
}

Revised: 04 March 2013; Accepted: 19 April 2013

\begin{abstract}
In industrial applications like cellulosic biofuel production, efficient degradation of cellulose is one of the major concerns. But the efficiencies of cellulose degradation by different types of biofilms are not yet explored. This study was carried out to determine whether the community actions of fungal-bacterial biofilms may increase the rates of cellulose bio-degradation. Cellulolytic fungi and bacteria were isolated from soils, composts and leaf litter and screened for simple sugar production. To identify efficient sugar producing communities, combinations of these isolates were tested in batch cultures of cellulose broth prepared with commercial cellulose. Three different communities; fungal and bacterial monocultures, fungal-bacterial biofilms and fungal mixed cultures were tested. The monoculture of Acremonium sp. was the highest sugar yielder among all tested microorganisms. Among fungal mixed cultures, Acremonium sp. with Fusarium sp. was an effective sugar yielder. Acremonium sp. with a Bacillus sp. was effective among fungal-bacterial biofilms. These three cultures were also inoculated into broth media prepared with Eupatorium odoratum or Panicum maximum or Lantana camara or Mimosa pigra to assess their simple sugar production from plant materials. The highest sugar production was by Acremonium sp. monoculture and the lowest was by the Acremonium sp. with Bacillus sp. biofilm. This was true for all four weeds. Thus, all the fungal-bacterial biofilms tested were comparatively less effective sugar producers.
\end{abstract}

Keywords: Bio-degradation, cellulose, fungal-bacterial biofilms, mixed-cultures, monocultures.

\section{INTRODUCTION}

The ever increasing demand for energy is one of the greatest challenges for humans. Fossil fuels, which have been the major energy source since the industrial revolution are dwindling rapidly and the increased use of fossil fuels has caused greenhouse gas emissions and created undesirable damage to the environment. The current instability of oil supplies and the continuous fluctuation of prices have further ignited widespread interest in alternative energy sources. Biofuels are among the promising transportation green energy sources for the future.

The extensive range of organic materials used for biofuel production include starch from cereal plants, lignocellulosic materials and algae etc. Biofuels are classified based upon the substrate used in their production. First generation biofuels are manufactured using starch from food-based cereal plants like corn and wheat; sugar from sugar cane; oil from the seeds of rape; soya bean and jatropha; vegetable oils and animal fats (Antizar-Ladislao \& Turrion-Gomez, 2008). Second generation biofuels also known as cellulosic biofuels, are produced using lignocellulosic materials like forest and crop residues, straw, municipal and construction waste (Antizar-Ladislao \& Turrion-Gomez, 2008). Both cyanobacteria and eukaryotic algae are extensively used in the production of third generation biofuels called algal biofuels and are becoming increasingly popular because their yields per unit area of land surpass those from all other feed stocks (Aristidou \& Penttila, 2000; $\mathrm{Hu}$ et al., 2008; Dellomonaco et al., 2010). Organic wastes are also used in biogas and biofuel production. However, the public opinion on producing biofuels from edible sources is not favourable. Hence, there is more interest on research into the development of less expensive methodologies to produce biofuels from nonedible sources like lignocellulosic biomasses of plants and organic wastes. 
Invasive weeds are probable raw materials for cellulosic biofuel production. These are non-indigenous or nonnative plants, which economically, environmentally, and ecologically affect the habitats and bioregions they invade (Westbrooks, 1998). Several types of invasive weeds are found in Sri Lanka. Among them Lantana camara L. and Mimosa pigra L. are two species present in abundance in the Central Province (Marambe, 2001). Panicum maximum L. and Eupatorium odoratum L. are also among the common invasive weeds (Gunasekera, 2008). If effective technologies can be developed to derive commercial products from these weeds, it will be beneficial both economically and ecologically, i.e. the constant pruning could improve the aesthetic appearance of their habitats. For industrial scale biofuel production, a continuous supply of raw materials should be assured. The fast growing nature of these weeds can provide raw materials in abundance for biofuel industries.

The hardwood structure of plant biomass consists of biopolymers like cellulose, hemicelluloses and lignin. Cellulose is the major component in the rigid cell walls of plants and is a linear polysaccharide polymer with many glucose monosaccharide units. An important feature of cellulose, relatively unusual in the polysaccharide world, is its crystalline structure. The difficulty of hydrolyzing this crystalline structure of cellulose into simple sugars is one of the major problems in the biofuel industry. Bioconversion, particularly enzymatic hydrolysis of these cellulosic materials into simple sugars has been a subject of intensive research. Cellulose degrading microfungi and biofilm technology are quite interesting fields to be researched for their potential applicability in biofuel industry.

Cellulase production by different cellulolytic microfungi is being vigorously studied for cost reduction strategies. Although a large number of microorganisms (fungi, bacteria and actinomycetes) are capable of degrading cellulose, only a few of them produce significant quantities of cell-free enzyme fractions capable of complete hydrolysis of cellulose in vitro. Cellulases obtained from compatible mixed cultures of fungi appear to have more enzyme activity as compared to their pure cultures and other combinations (Jayant et al., 2011). Therefore, extensive studies into bio-degradation by fungal mixed cultures and the monocultures of their constituent species would be beneficial in cellulosic biofuel production.

There is a possibility that microbial biofilms could also be used as agents of cellulose degradation due to their favourable properties. A biofilm is a complex aggregation of microorganisms, which is characterized by structural heterogeneity, genetic diversity, complex community interactions, and an extracellular matrix of polymeric substances (Flemming \& Wingender, 2001; Seneviratne et al., 2008; Wang \& Chen, 2009). They are usually found on solid substrates, submerged in or exposed to an aqueous solution (Sadashivaiah \& Mysore, 2010). Bacteria living in a biofilm can have significantly different properties from the same species that are free-living (Seneviratne et al., 2008). In the perspective of biodegradation, the extracellular matrix of biofilms provides a confined microenvironment, keeping substrate, enzymes, and microbes in close proximity (Flemming \& Wingender, 2001; Wang \& Chen, 2009). The extra-cellular polysaccharides in this matrix have a variety of binding sites for extracellular enzymes and substrate macromolecules, facilitating the extracellular enzymatic reactions (Sharon \& Lis, 1993; Stryer, 1995; Liu \& Tay, 2002; Wang \& Chen, 2009). There are several different types of biofilms depending on the organisms involved in biofilm formation. One common type of biofilm is fungal-bacterial biofilm in which the fungi act as the biotic surface to which the bacteria adhere (Seneviratne et al., 2008).

The advantages of biofilms include concentration of cell-associated hydrolytic enzymes at the biofilmsubstrate interface to increase the reaction rates, and the physiological synergy between fungi and bacteria offers the possibility of completing delignification and saccharification in one piece of biofilm. This type of synergy actually takes place in natural ecosystems (Sinsabaugh \& Linkins, 1990; Wang \& Chen, 2009) and in the rumen environment (Mcsweeney et al., 1994; Gordon \& Phillips, 1998; Wang \& Chen, 2009), facilitating the recycling of lignocellulosic materials. Symbiosis promotes maintenance of fungal delignification activity since bacteria digest the fungal delignification products that could have caused feedback inhibition (Rainey et al., 1990; Wang \& Chen, 2009). Fungal delignification benefits hydrolytic bacteria by increasing the accessibility of cellulose and hemicellulose wrapped inside the lignin structure (Mcsweeney et al., 1994; Gordon \& Phillips, 1998; Boer et al. 2005; Wang \& Chen, 2009). The use of bacterial-fungal synergy in a biofilm should be explored as a next step in delignification and saccharification integrated process development (Wang \& Chen, 2009). Another expected advantage of biofilm technology in biofuel industry is that it may increase the tolerance towards product inhibition. This is an important aspect as it has been shown that during saccharification, the increased simple sugar concentration can inhibit cellulase production (Krisch \& Szajani, 1997; Ciesarova et al., 1998; Jirku, 1999; Desimone et al., 2002; Zhou et al., 2008; Wang \& Chen, 2009). 
Although there are no records of utilizing biofilm based bioreactors in biofuel production processes like delignification, saccharification or to combine these two processes with fermentation, the production of enzymes, which are useful in cellulosic biofuel production has been accelerated by biofilm technology i.e. cellulase production by Trichoderma viride in spouted-bed reactor (Webb et al., 1986). The objective of this study was to compare the efficiency of fungal and bacterial monocultures with fungal-bacterial biofilms in the delignification and saccharification of plant substrates in order to subject the hydrolysate into biofuel production.

\section{METHODS AND MATERIALS}

\section{Isolation and screening of cellulose degrading microorganisms}

Cellulose degrading fungi and bacteria were isolated from soils, composts and leaf litter layers using $1 \%$ cellulose agar medium broth [1 $\mathrm{g}$ of cellulose powder (Fluka, analytical grade) $+1.5 \mathrm{~g}$ agar in $100 \mathrm{~mL}$ of mineral salt solution, $\mathrm{pH} \sim 7$ ] in which cellulose is the sole source of carbon. Mineral salts solution of following composition (gL) $\left(\mathrm{NH}_{4}\right)_{2} \mathrm{SO}_{4}(2.0), \mathrm{K}_{2} \mathrm{HPO}_{4}(1.0), \mathrm{MgSO}_{4} .7 \mathrm{H}_{2} \mathrm{O}(1.0)$, $\mathrm{NaCl}(1.0), \mathrm{CaCO}_{3}(0.25)$, and $1.0 \mathrm{~mL}$ of trace elements solution per litre was used. The isolates were screened for the most efficient cellulose degrading bacteria and fungi by inoculating each isolate in three replicates, into $1 \%$ cellulose broth $(1 \mathrm{~g}$ of cellulose in $100 \mathrm{~mL}$ of mineral salt medium, $\mathrm{pH} \sim 7$ ) in which the initial simple sugar content has been measured. A set of replicates of the same medium was left without inoculating and was used as the control. After incubating for $20 \mathrm{~d}$ at room temperature $\left(\sim 25{ }^{\circ} \mathrm{C}\right)$, the final sugar content was measured by the phenol-sulphuric method as described by Sadasivam \& Manickam (1996). The cellulose broth was kept still to enable cellulose particles to settle on the bottom of the flask. $1.0 \mathrm{~mL}$ from the supernatant was decanted into an eppendorf tube under sterile conditions. It was centrifuged at 6000 r.p.m (Harrier 18/80) to sediment the cellulose particles. $0.5 \mathrm{~mL}$ from the supernatant was decanted into a test tube and subjected to phenol sulphuric method (Sadasivam \& Manickam, 1996) by adding $0.5 \mathrm{~mL}$ of $5 \%$ phenol in $0.1 \mathrm{M} \mathrm{HCl}$ into $0.5 \mathrm{~mL}$ of sample. $2.5 \mathrm{~mL}$ of conc. $\mathrm{H}_{2} \mathrm{SO}_{4}$ was added and mixed thoroughly. The mixture was kept to cool and the absorbance was measured at $490 \mathrm{~nm}$. The final sugar yield was calculated by taking the difference between final and initial sugar concentrations. More efficient organisms (bacteria and fungi), which were able to produce high concentrations of monosaccharides were selected for further biofilm production (Table 1). The efficient fungi were also inoculated in lignin agar medium [ $1 \mathrm{~g}$ of lignin powder (Sigma, analytical grade) $+1.5 \mathrm{~g}$ agar in $100 \mathrm{~mL}$ of mineral salt, $\mathrm{pH} \sim 7$ ] in order to assess their capability of utilizing lignin as the sole source of carbon.

\section{Identification of cellulolytic micro-organisms}

The bacteria were presumptively identified by colony morphology, Grams stain, motility and biochemical tests according to the Bergey's Manual of Determinative Bacteriology (Holt et al., 1994). Fungi were tentatively identified using macroscopic and microscopic morphological characteristics. Slide culture technique was used to aid the fungal identifications.

\section{Biofilm development}

Each isolate of efficient cellulose degrading bacteria (selected after efficiency screening) was grown in $25 \mathrm{~mL}$ of nutrient broth (standard nutrient broth from Himedia) for $2 \mathrm{~d}$. Isolates of efficient cellulose degrading fungi were grown separately in $25 \mathrm{~mL}$ of potato dextrose broth for $1 \mathrm{wk}$. The bacteria and fungi were mixed with each other into desired combinations. Those mixed cultures were incubated for $21 \mathrm{~d}$ and observed under a light microscope once in every $2 \mathrm{~d}$ for fungal-bacterial film formation. Bacterial attachments along the fungal mycelium were taken as fungal-bacterial biofilms according to the definition by Seneviratne et al. (2008).

\section{Screening of different types of cultures}

The developed fungal-bacterial biofilms, combinations of several biofilms and single microbial cultures were screened for better simple sugar producers by inoculating into $1 \%$ cellulose broth (mineral salt solution $100 \mathrm{~mL}$ + cellulose powder $1.0 \mathrm{~g}, \mathrm{pH} \sim 7$ ) in three replicates. The initial simple sugar content of the cellulose broth was measured before inoculation. The cultures were incubated at room temperature $\left(\sim 25^{\circ} \mathrm{C}\right)$ for $5-6$ wks. In order to aerate the cultures during incubation, regular shaking (3-5 times per day) of the cultures was done manually. The simple sugar content in each culture was measured as described earlier. The cultures employed in screening were batch cultures. Therefore, negative feedbacks were also observed. In order to calculate the average sugar yield per week, harmonic mean was used. The highest sugar yielders among fungal monocultures, fungal mixed cultures and fungal-bacterial biofilms were selected to inoculate into plant substrates. 
Table 1: Genera of 10 most efficient cellulose degrading fungi and bacteria with their simple sugar yields during the initial screening

\begin{tabular}{|c|c|c|c|c|}
\hline $\begin{array}{l}\text { Type of } \\
\text { microorganism }\end{array}$ & Source & Generic name & Code no & $\begin{array}{c}\text { Simple sugar } \\
\text { concentration } \\
(\mathrm{mmol} / \mathrm{L})\end{array}$ \\
\hline \multirow[t]{10}{*}{ Fungi } & Garden soil & Acremonium sp. & F23 & 0.2998 \\
\hline & Compost & Fusarium sp. & $\mathrm{F} 12$ & 0.2674 \\
\hline & Compost & Aspergillus sp. & $\mathrm{F} 15$ & 0.2502 \\
\hline & Compost & Mucor sp. & F5 & 0.2286 \\
\hline & Compost & Aspergillus sp. & F2 & 0.2204 \\
\hline & Compost & Aspergillus sp. & F9 & 0.2071 \\
\hline & Compost & Trichoderma sp. & F8 & 0.1601 \\
\hline & Leaf litter & Penicillium sp. & F52 & 0.1345 \\
\hline & Compost & Fusarium sp. & F97 & 0.0366 \\
\hline & Compost & Graphium sp. & F99 & 0.0324 \\
\hline \multirow[t]{10}{*}{ Bacteria } & Leaf litter & Listeria sp. & B90 & 0.1108 \\
\hline & Leaf litter & Bascillus sp. & B91 & 0.0793 \\
\hline & Leaf litter & Bascillus sp. & B89 & 0.0696 \\
\hline & Compost & Alcaligenes sp. & B16 & 0.0623 \\
\hline & Compost & Alcaligenes sp. & B5 & 0.0438 \\
\hline & Leaf litter & Neisseria spp. & B97 & 0.0397 \\
\hline & Garden soil & Alcaligenes sp. & B36 & 0.0275 \\
\hline & Compost & Neisseria sp. & B3 & 0.0257 \\
\hline & Garden soil & Listeria sp. & B43 & 0.0217 \\
\hline & Leaf litter & Streptococcus sp. & B99 & 0.0214 \\
\hline
\end{tabular}

\section{Biodegradation of selected weed material}

Four invasive weeds, E. odoratum, $P$. maximum, L. camara and M. pigra were selected for the degradation studies because of their abundance in Sri Lanka. The above ground parts of the weeds were collected as the substrate. The washed, dried and ground plant substrate of each weed was prepared separately into $5 \%$ weed media by mixing with distilled water. The media were sterilized and their $\mathrm{pH}$ and initial simple sugar concentrations were measured. The weed media were slightly acidic with $\mathrm{pH} \sim 5.5-6$. Each weed medium was inoculated separately with broth cultures of microorganisms selected after screening in three replicates (Table 4). They were incubated at room temperature for $15 \mathrm{wks}$ with regular manual shaking (3-5 times per day). The simple sugar yield in each culture was measured weekly. Once a week, half of the liquid in the medium was removed and replaced with sterile distilled water. It was done after keeping the culture still to sediment the substrate. Removal of the substrate and aggregated fungal mycelium was avoided as much as possible to minimize negative feed backs due to accumulation of sugar products from breakdown of cellulose. At the end of the incubation period, cumulative sugar yields were calculated. Statistical analyses were done using Minitab 14 statistical analysis software. 


\section{RESULTS AND DISCUSSION}

All the isolates exhibited the capability of growing in cellulose agar medium in which the sole source of carbon was cellulose. However, the screening revealed that some organisms were more efficient in simple sugar production than others. The amount of simple sugar produced and released to the medium can depend on the activities of cellulase systems and physiological characteristics of the particular species. The genera of the cellulose degrading fungi which were found to be efficient were Acremonium, Fusarium, Aspergillus, Mucor, Trichoderma, Penicillium and Graphium (Table 1). The efficient cellulose degrading bacterial isolates were Bacillus, Listeria, Alcaligenes, Neisseria and Streptococcus (Table 1).
Acremonium sp. (F23) was the isolate, which produced the highest simple sugar concentration (Table 2). The analysis of variance (culture type $v s$ harmonic mean) showed that the differences in sugar yields (alpha was set at 0.05$)$ were significant $(F=11.90$ and $p=0.000)$. Post hoc comparison with Hsu's MCB (multiple comparisons with the best) revealed that the Acremonium sp. (F23 fungal monoculture) was significantly higher in its sugar yield. Among fungal mixed cultures also a similar situation was observed (Table 3 ). The analysis of variance of tested fungal mixed cultures (no. of fungi in the culture $v s$ harmonic mean) showed that the differences in sugar yields (alpha was set at 0.05) were significant $(\mathrm{F}=67.01, \mathrm{p}=0.000)$. Post hoc comparison with Hsu's MCB indicated that the Acremonium spp. (F23 fungal

Table 2: Sugar production from commercial cellulose by the most efficient cellulose degrading fungi, three efficient bacteria and biofilms made by combinations of these organisms

\begin{tabular}{|c|c|c|c|c|c|c|c|c|}
\hline \multirow[t]{2}{*}{ Microbial combination } & \multirow[t]{2}{*}{$\begin{array}{l}\text { Culture } \\
\text { type }\end{array}$} & \multicolumn{6}{|c|}{$\begin{array}{l}\text { Sugar concentration (Weekly) } \\
\qquad(\mathrm{mmol} / \mathrm{L})\end{array}$} & \multirow[t]{2}{*}{$\begin{array}{l}\text { Harmonic } \\
\text { mean }\end{array}$} \\
\hline & & At start & $2^{\text {nd }}$ Week & $3^{\text {rd }}$ Week & $4^{\text {th }}$ Week & $5^{\text {th }}$ Week & $6^{\text {th }}$ Week & \\
\hline Control & $\mathrm{C}$ & 0.0143 & 0.0147 & 0.0145 & 0.0145 & 0.0135 & 0.0126 & $0.0139(0.00)$ \\
\hline B89 & B & 0.0143 & 0.0323 & 0.0394 & 0.0437 & 0.0439 & 0.0292 & $0.0367(0.00)$ \\
\hline B91 & B & 0.0143 & 0.0642 & 0.0373 & 0.0426 & 0.0298 & 0.0721 & $0.0441(0.00)$ \\
\hline B90 & B & 0.0143 & 0.0534 & 0.0333 & 0.0872 & 0.0956 & 0.0772 & $0.0598(0.01)$ \\
\hline F23 & $\mathrm{F}^{*}$ & 0.0143 & 0.1042 & 0.0886 & 0.1034 & 0.1901 & 0.1826 & $0.1211(0.02)$ \\
\hline F23 B89 B90 & FBB & 0.0143 & 0.0665 & 0.0827 & 0.0952 & 0.0986 & 0.0520 & $0.0746(0.01)$ \\
\hline F23 B91 B89 B90 & FBB & 0.0143 & 0.0529 & 0.0601 & 0.0638 & 0.0691 & 0.0706 & $0.0626(0.00)$ \\
\hline B91 B89 B90 & $\mathrm{BC}$ & 0.0143 & 0.0360 & 0.0352 & 0.0374 & 0.0403 & 0.0600 & $0.0402(0.00)$ \\
\hline F23 B91 & FBB & 0.0143 & 0.0906 & 0.0461 & 0.0633 & 0.0700 & 0.1260 & $0.0707(0.01)$ \\
\hline F23 B90 & FBB & 0.0143 & 0.0738 & 0.0353 & 0.0590 & 0.0893 & 0.1346 & $0.0646(0.01)$ \\
\hline F23 B89 & FBB & 0.0143 & 0.0630 & 0.0773 & 0.0933 & 0.0911 & 0.1001 & $0.0827(0.01)$ \\
\hline F15 B89 & FBB & 0.0143 & 0.0525 & 0.0499 & 0.0751 & 0.0778 & 0.0410 & $0.0558(0.00)$ \\
\hline F12 B89 & FBB & 0.0143 & 0.0458 & 0.0570 & 0.0600 & 0.0850 & 0.0358 & $0.0522(0.00)$ \\
\hline F15 B90 & FBB & 0.0143 & 0.0498 & 0.0720 & 0.0828 & 0.0858 & 0.0452 & $0.0627(0.01)$ \\
\hline F12 B90 & FBB & 0.0143 & 0.0395 & 0.0744 & 0.0890 & 0.0524 & 0.0699 & $0.0600(0.01)$ \\
\hline F23 B89 \& F12 B90 & $2 * \mathrm{FBB}$ & 0.0143 & 0.0590 & 0.0810 & 0.1001 & 0.0533 & 0.0790 & $0.0707(0.01)$ \\
\hline $\begin{array}{l}\text { F23 B89 \& F12 B90 \& } \\
\text { F15 B89 }\end{array}$ & $3 * \mathrm{FBB}$ & 0.0143 & 0.0500 & 0.0599 & 0.0884 & 0.0810 & 0.0706 & $0.0671(0.01)$ \\
\hline
\end{tabular}

FBB: Fungal bacterial biofilm; 2*FBB: Two biofilms; 3*FBB: Three biofilms; BC: Bacterial mixed culture;

$\mathrm{F}^{*}$ - Acremonium sp. fungal monoculture; B: Bacterial monoculture; C: Control; Values within parentheses are standard errors 
monoculture) and the mixed culture of three fungi (F23 F12 F15) were superior to all the other monocultures and mixed cultures. These two were not significantly different from each other in their effectiveness. The highest recorded simple sugar concentration within a week was observed in co-cultures having two fungal species, F23 F12 and F23 F15; in the third week a slightly higher sugar concentration than that of F23 monoculture was observed although the increase was not statistically significant $(\mathrm{F}=0.64, \mathrm{p}=0.571)$.

Most of the genera examined in prior research have been reported for their cellulose degrading ability. Sirisena and Manamendra (1995) have reported cellulolytic activities of Listeria sp. (along with Enterobacteria and Pseudomonas isolates). Vazquez-Arista et al. (1997) have reported Alcaligenes spp. among cellulolytic bacteria isolated from the digestive system of a Coleopteran. Although direct evidence on cellulolytic activities of Neisseria were not found in literature, an enzyme catalyzing the hydrolysis of beta-1,4 bonds in cellulose acetate has been purified by Moriyoshi et al. (2002) from Neisseria sicca. Oyeleke and Okusanmi (2008) have isolated P. aeruginosa, Streptococcus, Bacillus, Penicillium, Aspergillus, Mucor and Fusarium species, which were able to hydrolyze cellulose. The filamentous fungi Acremonium cellulolyticus and Trichoderma reesei are well known to be potential cellulase producers (Fujii et al., 2009).

According to the preliminary screening, the fungal isolates F23, F12 and F15 and the bacterial isolates B90, B91 and B89 produced high sugar yields during the screening (Table 1). These organisms were subjected to fungal-bacterial biofilm formation and the isolate combinations F23-B91, F23-B90, F23-B89, F12-B89, F12-B90, F15-B89 and F15-B90 were successful in producing biofilms.

Table 3: Sugar production from commercial cellulose by cultures of efficient cellulose degrading fungi

\begin{tabular}{|c|c|c|c|c|c|c|c|c|}
\hline \multirow[t]{2}{*}{ Fungal combination (code no.) } & \multirow[t]{2}{*}{$\begin{array}{l}\text { No. of fungi } \\
\text { included }\end{array}$} & \multicolumn{6}{|c|}{$\begin{array}{l}\text { Sugar concentration } \\
\qquad(\mathrm{mmol} / \mathrm{L})\end{array}$} & \multirow[t]{2}{*}{$\begin{array}{c}\text { Harmonic } \\
\text { mean }\end{array}$} \\
\hline & & At start & $2^{\text {nd }}$ Week & $3^{\text {rd }}$ Week & $4^{\text {th }}$ Week & $5^{\text {th }}$ Week & $6^{\text {th }}$ Week & \\
\hline F23 & $\mathrm{F}^{*}$ & 0.0114 & 0.0704 & 0.0890 & 0.2032 & 0.1926 & 0.1083 & 0.1116 \\
\hline F12 & 1 & 0.0114 & 0.0390 & 0.0587 & 0.1861 & 0.0743 & 0.0923 & 0.0691 \\
\hline F15 & 1 & 0.0114 & 0.0418 & 0.0587 & 0.1685 & 0.0891 & 0.0829 & 0.0712 \\
\hline F52 & 1 & 0.0114 & 0.0331 & 0.0476 & 0.1489 & 0.1059 & 0.1051 & 0.0650 \\
\hline F23 F12 & 2 & 0.0114 & 0.0441 & 0.0769 & 0.2138 & 0.1685 & 0.1128 & 0.0907 \\
\hline F23 F12 F15 & 3 & 0.0114 & 0.0658 & 0.1123 & 0.1858 & 0.0909 & 0.1295 & 0.1037 \\
\hline F23 F12 F15 F5 & 4 & 0.0114 & 0.0693 & 0.0587 & 0.0893 & 0.1346 & 0.1175 & 0.0853 \\
\hline F23 F12 F15 F5 F2 & 5 & 0.0114 & 0.0311 & 0.0406 & 0.0797 & 0.1159 & 0.1018 & 0.0570 \\
\hline F23 F12 F15 F5 F2 F52 & 6 & 0.0114 & 0.0331 & 0.0418 & 0.0839 & 0.1207 & 0.0977 & 0.0591 \\
\hline F23 F12 F15 F5 F2 F52 F8 & 7 & 0.0114 & 0.0362 & 0.0423 & 0.0863 & 0.1127 & 0.0877 & 0.0601 \\
\hline F23 F12 F15 F5 F2 F52 F8 F9 & 8 & 0.0114 & 0.0443 & 0.0455 & 0.0914 & 0.1161 & 0.0944 & 0.0670 \\
\hline F23 F12 F15 F52 & 4 & 0.0114 & 0.0612 & 0.0506 & 0.0867 & 0.1312 & 0.0883 & 0.0751 \\
\hline F23 F15 & 2 & 0.0114 & 0.0697 & 0.0637 & 0.2049 & 0.0796 & 0.1391 & 0.0915 \\
\hline Control & $\mathrm{C}$ & 0.0114 & 0.0100 & 0.0106 & 0.0116 & 0.0104 & 0.0107 & 0.0106 \\
\hline
\end{tabular}

$\mathrm{F}^{*}$ : Acremonium sp. fungal monoculture; C: Control 
The cellulose degrading ability and sugar producing pattern of these fungal-bacterial biofilms, fungal mixed cultures and some fungal/bacterial monocultures in commercial cellulose were tested and the results are presented in Tables 2 and 3. Unlike the fungalbacterial biofilms, fungal-fungal biofilms are not easily identifiable under the light microscope. Hence random combinations of fungal mixed cultures were employed in this study.

According to the results, the recorded highest sugar concentration was observed with Acremonium sp. (F23) monoculture. The biofilms and fungal mixed cultures tested in this study were unable to exhibit increased sugar production rates than Acremonium sp. (F23). All the bacterial isolates were significantly less efficient in saccharification of cellulose compared to the most efficient fungi, which ranked from $1^{\text {st }}-8^{\text {th }}$ in the initial screening (Table 1). Therefore, the incorporation of these bacteria into more efficient fungi may have reduced the sugar yields of fungal monocultures by simply utilizing the sugars available in the cultures. In fungal mixed cultures also less sugar yields were observed compared to Acremonium sp. monoculture, probably due to the less efficient organisms utilizing the simple sugars liberated into the medium.

Table 4: Cultures selected for inoculation into weed substrates

\begin{tabular}{lll}
\hline Selected culture & Organisms involved & Reasons for the selection \\
\hline F 23 & Acremonium sp. monoculture & Highest harmonic mean of sugar yield \\
& Highest recorded sugar concentration in a week \\
F23 B89 & Highest harmonic mean of sugar yield \\
F23 F12 & Acremonium sp. and Fusarium sp. mixed culture & Highest recorded sugar concentration in a week \\
& & Third highest harmonic mean of sugar yield \\
\hline
\end{tabular}

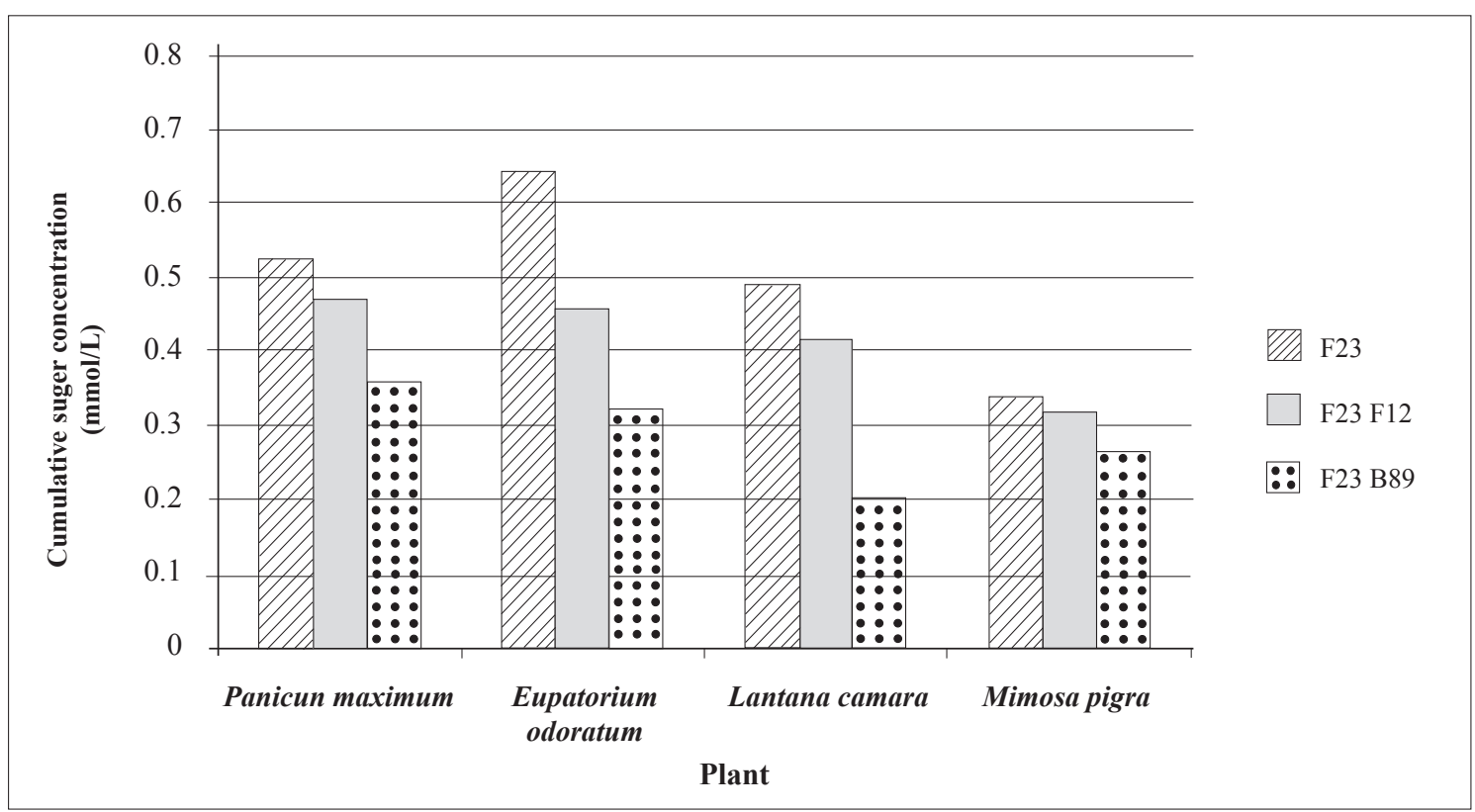

Figure 1: Cumulative sugar yield in all four weed substrates by the three selected microbial cultures Statistical analysis of above data with two way analysis of variance (cumulative yields $v s$ plant, culture; alpha set at 0.05 ) indicates that the differences were significant with $\mathrm{F}=12.03$ and $\mathrm{p}=0.008$. No significant difference among plant substrates due to one way ANOVA (cumulative yields $v$ plant) with $\mathrm{F}=1.24$ and $\mathrm{p}=0.357$. 
Considering all the observations from simple sugar analysis in commercial cellulose, three different cultures were selected for the inoculation of weed substrates. The selected culture, nature of the culture and the reasons for theselectionaresummarizedinTable4. Thesecultureswere inoculated into weed substrates; Eupatorium, Panicum, Lantana and Mimosa in submerged cultures. These weeds were selected as raw material for degradation studies due to their abundance and harmful effects on the Sri Lankan environment. Weed substrates were not chemically pretreated for delignification. Yet Acremonium sp. and Fusarium sp. had the ability to degrade lignin as both of them were capable of growing in lignin medium in the absence of any other carbon source. In contrast to the batch culturing method employed with commercial cellulose, manually maintained continuous cultures were used with weed substrates in order to get the maximum sugar yield by reducing the negative feed backs due to accumulation of the product. The cumulative sugar yield of each plant and each microbial culture inoculated into plant substrates was calculated and analyzed (Figure 1). One way ANOVA showed that the differences of the cumulative yields of different cultures were significant with $\mathrm{F}=5.41$ and $\mathrm{p}=0.029$. Hsu's MCB revealed that the tested biofilm was significantly less effective but the cumulative yields of the fungal mixed culture and F23 monoculture were not significantly different from each other (Figure 1).

In plant substrates both cellulose and hemicelluloses are present. Cellulase systems are capable of degrading hemicelluloses as well as cellulose (Lynd et al., 2002). Therefore, the simple sugar yield during the plant substrate degradation can be attributed to degradation of both cellulose and hemicelluloses. The highest sugar yield was provided by the Acremonium sp. (F23) monoculture in all four plant substrates. The sugar yields of $E$. odoratum and $P$. maximum were higher than that of M. pigra and L. camara probably due to their less lignified soft nature of the tissues. Hence, for biofuel production E. odoratum and $P$. maximum can serve as better raw material sources than the other two species. All the microbial communities that were tested during this research were unable to increase the rate of cellulose degradation through community actions. The biofilms and the fungal combinations tried were perhaps not showing any synergistic effect towards saccharification process and hence further research is required in this field.

\section{CONCLUSION}

The screening of fungal and bacterial isolates for effective organisms revealed that the ten most efficient cellulose degrading fungal isolates were Acremonium sp., two Fusarium spp., three Aspergillus spp., Mucor sp., Trichoderma sp., Penicillium sp. and Graphium sp. The most efficient cellulose degrading bacteria included two Listeria spp., two Bacillus spp., three Alcaligenes spp., two Neisseria spp. and a Streptococcus sp. Among them cellulose degrading fungal species (ranked $1^{\text {st }}-8^{\text {th }}$ ) were more effective than the bacteria (i.e. B90, B91 and B89).

Acremonium sp. (F23) monoculture was the most efficient simple sugar yielder compared to other single and mixed microbial cultures. Its efficiency did not increase when incorporated into fungal-bacterial biofilms or fungal mixed cultures. All the microbial communities that were tested during this study were unable to increase the rate of cellulose degradation through community actions.

In the simple sugar production by microbial cellulose degradation, E. odoratum and P. maximum produced higher sugar yields than the other two weeds. Therefore, E. odoratum and P. maximum are better raw materials than L. camara and M. pigra for use in the production of cellulosic biofuels.

\section{Aknowledgement}

The authors thank Ms Kumuduni Karunaratne, Technical Officer, M.A. Lal, Work Assistant and the volunteer students Ishani Samanthika and Savinidini Amunugama for their assistance in sample preparation and analysis.

\section{REFERENCES}

1. Antizar-Ladislao B. \& Turrion-Gomez J.L. (2008). Second-generation biofuels and local bioenergy systems. Biofuels, Bioproducts and Biorefining 2(05): 455 - 469.

2. Aristidou A. \& Penttila M. (2000). Metabolic engineering applications to renewable resource utilization. Current Opinion on Biotechnology 11(02):187-198.

3. Boer W.D, Folman L.B., Summerbell R.C. \& Boddy L. (2005). Living in a fungal world: impact of fungi on soil bacterial niche development. FEMS Microbiology Reviews 29(04): $795-811$.

4. Ciesarova Z., Domeny Z., Smogrovicova D., Patkova J. \& Sturdik E. (1998). Comparison of ethanol tolerance of free and immobilized Saccharomyces uvarum yeasts. Folia Microbiologica 43(01): 55 - 58.

5. Dellomonaco C., Fava F. \& Gonzalez R. (2010). The path to next generation biofuels: successes and challenges in the era of synthetic biology. Review. Microbial Cell Factories 9: 3.

6. Desimone M.F., Degrossi J., D'Aquino M. \& Diaz L.E. (2002). Ethanol tolerance in free and sol-gel immobilized 
Saccharomyces cerevisiae. Biotechnology Letters 24(19): 1557 - 1559.

7. Flemming H.C. \& Wingender J. (2001). Relevance of microbial extracellular polymeric substances (EPSs) Part I: structural and ecological aspects. Water Science and Technology 43(06): $1-8$.

8. Fujii T., Fang X., Inoue H., Murakami K. \& Sawayama S. (2009). Enzymatic hydrolyzing performance of Acremonium cellulolyticus and Trichoderma reesei against three lignocellulosic materials. Biotechnology for Biofuels 2(1): 24.

9. Gordon G.L.R. \& Phillips M.W. (1998). The role of anaerobic gut fungi in ruminants. Nutrition Research Reviews 11(01): 133 - 168.

10. Gunasekera L. (2008). Identification guide for invasive plants in Sri Lanka, $1^{\text {st }}$ edition, pp. 125. Print \& Print graphics (Pvt.) Ltd., Colombo 10.

11. Holt J.G., Krieg N.R., Sneathm P.H.A., Staley J.T. \& Williams S.T. (1994). Bergey's Manual of Determinative Bacteriology, $9^{\text {th }}$ edition, pp. 787. Williams and Williams, Baltimore, USA.

12. Hu Q., Sommerfeld M., Jarvis E., Ghirardi M., Posewitz M., Seibert M. \& Darzins A. (2008). Microalgal triacylglycerols as feedstocks for biofuel production: Perspectives and advances. The Plant Journal 54 (04): 621- 639 .

13. Jayant M., Rashmi J., Shailendra M. \& Deepesh Y. (2011). Production of cellulase by different co-culture of Aspergillus niger and Penicillium chrysogenum from waste paper, cotton waste and baggase. Journal of Yeast and Fungal Research 2(02): 24 - 27.

14. Jirku V. (1999). Whole cell immobilization as a means of enhancing ethanol tolerance. Journal of Industrial Microbiology and Biotechnology 22(03):147 - 151.

15. Krisch J. \& Szajani B. (1997). Ethanol and acetic acid tolerance in free and immobilized cells of Saccharomyces cerevisiae and Acetobacter aceti. Biotechnology Letters 19(06):525 - 528.

16. Liu Y. \& Tay J.H. (2002). The essential role of hydrodynamic shear force in the formation of biofilm and granular sludge. Water Research 36(07):1653-1665.

17. Lynd L.R., Weimer P.J., Zyl W.H.V. \& Pretorius I.S. (2002). Microbial cellulose utilization: fundamentals and biotechnology. Microbiology and Molecular Biology Reviews 66(03): 506 - 577.

18. Marambe B. (2001) Alien invasive plants in the central province of Sri Lanka. Sri Lankan Biodiversity Review 1: $21-30$.

19. Mcsweeney C.S., Dulieu A., Katayama Y. \& Lowry J.B. (1994). Solubilization of lignin by the ruminal anaerobic fungus Neocallimastix patriciarum. Applied Environmental Microbiology 60(08): 2985 - 2989.

20. Moriyoshi K., Ohmoto T., Ohe T. \& Sakai K. (2002). Purification and characterization of an endo-1,4-betaglucanase from Neisseria sicca SB that hydrolyzes beta-
1,4 linkages in cellulose acetate. Bioscience, Biotechnology \& Biochemistry 66(3): $508-515$.

21. Oyeleke S.B. \& Okusanmi T.A. (2008). Isolation and characterization of cellulose hydrolyzing microorganism from the rumen of ruminants. African Journal of Biotechnology 7(10): 1503 - 1504.

22. Rainey P.B., Cole A.L.J., Fermor T.R. \& Wood D.A. (1990). A model system for examining involvement of bacteria in basidiome initiation of Agaricus-bisporus. Mycological Research 94(02):191 - 195.

23. Sadashivaiah A.B. \& Mysore V. (2010). Biofilms: Their role in dermal fillers. Journal of Cutaneous and Aesthetic Surgery 3(01): 20 - 22.

24. Sadasivam S. \& Manickam A. (1996). Biochemical Methods, $1^{\text {st }}$ edition, p. 10. New Age International Limited Publishers, New Delhi, India.

25. Seneviratne G., Zavahir J.S., Bandara W.M.M.S. \& Weerasekara M.L.M.A.W. (2008). Fungal-bacterial biofilms: their development for novel biotechnological applications. World Journal of Microbiology and Biotechnology 24(06): $739-743$.

26. Sharon N. \& Lis H. (1993). Carbohydrates in cell recognition. Scientific American 268(01): 82 - 89.

27. Sinsabaugh R.L. \& Linkins A.E. (1990). Enzymatic and chemical-analysis of particulate organic-matter from a boreal river. Freshwater Biology 23(02): 301-309.

28. Sirisena D.M. \& Manamendra T.P. (1995). Isolation and characterization of cellulolytic bacteria from decomposing rice straw. Journal of National Science Council Sri Lanka 23(1): $25-30$.

29. Stryer L. (1995). Biochemistry, $4^{\text {th }}$ edition, pp. $189-191$. Freeman, New York, USA.

30. Vazquez-Arista M., Smith R.H., Olalde-Portugal V., Hinojosa R. E., Hernandez-Delgadillo R. \& Blanco-Labra A. (1997). Cellulolytic bacteria in the digestive system of Prostephanus truncatus (Coleoptera: Bostrichidae). Journal of Economic Entomology 90(5): 1371-1376.

31. Wang Z.W. \& Chen S. (2009). Potential of biofilmbased biofuel production. Applied Microbiology and Biotechnology 83(01): 1-18.

32. Webb C., Fukuda H. \& Atkinson B. (1986). The production of cellulase in a spouted bed fermentor using cells immobilized in biomass support particles. Biotechnology and Bioengineering 28(1): 41-50.

33. Westbrooks R. (1998). Invasive Plants, Changing the Landscape of America: Fact Book, p. 3. Federal Interagency Committee for the Management of Noxious and Exotic Weeds (FICMNEW), Washington D.C., USA. Available at http://digitalcommons.usu.edu/cgi/ viewcontent.cgi? article $=1489 \&$ context $=$ govdocs

34. Zhou B., Martin G.J.O. \& Pamment N.B. (2008). Increased phenotypic stability and ethanol tolerance of recombinant Escherichia coli KO11 when immobilized in continuous fluidized bed culture. Biotechnology and Bioengineering 100(04): $627-633$. 